\title{
Transactional Sex and HIV Incidence in a Cohort of Young Women in the Stepping Stones Trial
}

Rachel Jewkes ${ }^{1,4 *}$, Kristin Dunkle ${ }^{2}$, Mzikazi Nduna ${ }^{3}$ and Nwabisa Jama Shai ${ }^{1}$

${ }^{1}$ Gender \& Health Research Unit, Medical Research Council, Pretoria, South Africa

${ }^{2}$ Rollins School of Public Health, Emory University, Atlanta, GA, USA

${ }^{3}$ Department of Psychology, University of the Witwatersrand, South Africa

${ }^{4}$ School of Public Health, University of the Witwatersrand, South Africa

\begin{abstract}
Background: Structural drivers of the HIV epidemic are increasingly recognised, and cross-sectional research has shown an association between transactional sex and HIV prevalence, but evidence on the impact of transactional sex on HIV incidence in young women remains limited.
\end{abstract}

Methods: We tested hypotheses that transactional sex predicted incident HIV infections in a dataset of 1077 HIV negative women aged 15-26 enrolled in a cluster randomised controlled trial. Incidence rate ratios were derived from multivariable Poisson models which included terms for age, HSV2, relationship power, condom use, intimate partner violence (IPV) exposure, treatment, stratum and person years of exposure to HIV.

Results: 127 sexually active women acquired HIV during the study. HIV incidence was greater among women having transactional sex with a once off partner (IRR $3.2995 \% \mathrm{Cl} 1.02,10.55, \mathrm{p}=0.046)$ and those having transactional sex with an on-going, concurrent partner (IRR $2.0595 \% \mathrm{Cl} 1.20,3.52, p=0.009$ ). An analysis was performed to distinguish between the effects of a transactional sexual encounter or relationship and having a higher number of sexual partners or older partners, which are usually entailed in transactional sex. Women having transactional sex with a casual partner (on-going or once off) and two or more partners during follow up had an elevated risk of HIV acquisition (IRR $2.2395 \% \mathrm{Cl} 1.28,3.88, \mathrm{p}=0.005$ ), where as those just having two or more partners did not (IRR $1.2095 \% \mathrm{Cl} 0.81,1.77, \mathrm{p}=0.368$ ). Women with partners 5 or more years older did not have an elevated risk of HIV.

Conclusions: Transactional sex with an on-going or once off partner elevates young women's risk of HIV infection. This finding is independent of partner number or age. These findings support the need for structural interventions in HIV prevention, with a stronger focus on reducing transactional sex.

\section{Introduction}

Women who engage in sex motivated by economic gain, whether in prostitution or more informal transactional sex, are very vulnerable to sexually transmitted infections, including HIV, as well as rape and intimate partner violence (IPV) [1-7]. The high HIV prevalence found in women in prostitution, compared to women in the general population has been recognised since the early days of the HIV epidemic and pertains globally. The contribution of transactional sex to HIV incidence amongst young women is less well described, although there is evidence from one longitudinal study of agricultural workers in Kenya [8].

Transactional sex has often not been studied and at times has been subject to overly simple measures and somewhat arbitrary definitions, for example conflating material gain and age difference between partners [9-11]. There has also been some confusion among researchers about the intersections of 'prostitution' or 'sex work' and 'transactional sex', as these are complex and highly contested [1214]. Women in prostitution (or sex work) may actively soliciting sex in a public area, brothel or embrace an identity as a 'prostitute' or 'sex worker', but do not do so always. In transactional sex there is generally an absence of prior negotiation of price, but price may be agreed $[14,15]$. In transactional sex, a wide range of goods or services, such as transport or accommodation, may be received in exchange for sex, but most commonly cash is given $[3,12,14]$. Whilst one off acts of sex for material gain are found, transaction may be the primary motivation for on-going relationships with secondary partners. In South Africa these are generally called khwapheni or nyatsi (in the Nguni or Sotho group languages and kept secret), and it may be a primary motivation for relationships with main partners $[2,12,16]$. In the latter case it can be very hard to distinguish transactional relationships from other relationships where there is a predominant expectation of both the man and the woman is that the man will fulfil a provider role, especially as the roles of romantic love, habit, social expedience etc in sustaining relationships are complex, and love may be expressed in gifts [16]. Yet research suggests that in these relationships men perceive an entitlement to sex because of their role as providers and women perceive that without material benefit their relationship would not be sustained. The potential for mismatch between perceptions of motivation is clearly shown in South Africa where men much more often report perceiving themselves to be in transactional relationships than women describe their own relationships or sex was predicated on material gain, at least in research $[3,9,12]$. Whilst authors assert that transactional sex is ubiquitous in Africa [17], there is huge variability in its actual prevalence and population-based prevalence studies of women have not shown it to be admitted to by the majority [9].

As a risk factor for HIV, transactional sex overlaps with several

${ }^{*}$ Corresponding author: Rachel Jewkes, Professor, Gender \& Health Research Unit, Medical Research Council, Private Bag X385, Pretoria 0001, South Africa, Tel: 012339 8525; Fax: 012339 8582; E-mail: rjewkes@mrc.ac.za

Received May 24, 2012; Accepted June 25, 2012; Published June 27, 2012

Citation: Jewkes R, Dunkle K, Nduna M, Shai NJ (2012) Transactional Sex and HIV Incidence in a Cohort of Young Women in the Stepping Stones Trial. J AIDS Clinic Res 3:158. doi:10.4172/2155-6113.1000158

Copyright: ( 2012 Jewkes R, et al. This is an open-access article distributed unde the terms of the Creative Commons Attribution License, which permits unrestricted use, distribution, and reproduction in any medium, provided the original author and source are credited. 
other dimensions of risk for women. Women who have transactional sex generally have more sexual partners than other women, and these relationships are commonly parts of webs of concurrency, although many secondary sexual relationships are not transactional $[3,18]$. Transactional relationships are stereotypically marked by substantial age differences between partners (as in the sugar daddy), and this is associated with a higher HIV prevalence [19,20,21], but many young men also engage in transactional sex with similar aged women $[2,14,16]$. Further sex may be transacted for alcohol in bars, in contexts after drinking where condom use is less likely to occur [22]. Men who engage in these relationships and acts are substantially more controlling, patriarchal and violent than other men [2,23]. In order to understand the contribution of the transactional nature of these relationships to HIV risk it is important to try to disentangle the relative contributions of these other factors where this is possible. Where this is not, we must acknowledge that the transactional element of these relationships may render women, and sexual networks, vulnerable through other dimensions of risk, including impact on network level concurrency (i.e. the density of concurrency across a network of sexually connected individuals).

Understanding the contribution of transactional sex to HIV incidence, and addressing it, remains particularly important because young women are much less able to change their own risk of HIV than older women and men. They lack power to negotiate condoms, are not able to individually benefit from male circumcision and evidence on anti-retroviral prevention, after the vaginal microbicide with tenofovir arms were dropped from the VOICE trial due to lack of evidence of effect, is disappointing. Whilst they may be able to benefit from their male partners testing for HIV and entering treatment programmes, evidence suggests that men who are most socially conservative, and even more so those who are violent and anti-social, are least likely to test and yet are over represented in among men who have transactional sex $[24,25]$.

Programming to prevent transactional sex in a context of considerable material poverty is challenging. Thus it is essential to better understand the contribution of this behaviour to HIV acquisition. The dataset from the evaluation of the HIV prevention intervention Stepping Stones in South Africa [26] presents an opportunity to examine empirically the hypotheses that HIV negative women who engage in various forms of transactional sex are independently more likely to acquire HIV during a period of prospective follow up. The dataset contains several measures of transactional sex as well as information on partner numbers and age difference, and HIV sero-status measured over two years. In this paper we present a longitudinal analysis of data from 1077 young rural South African women from this trial who were HIV negative at baseline, sexually active during the period of observation and had subsequent HIV tests. We examine two hypotheses. The first is that HIV negative women who have transactional sex are at increased risk of HIV acquisition. The second is that HIV negative women who have more 2 or more sexual partners and transactional sex have a higher risk of HIV acquisition than women who just have two or more partners, and higher risk than those having a partner 5 or more years older (when having transactional sex with a casual partner has been adjusted for). We have previously shown that intimate partner violence exposure, relationship power inequity, and HSV2 infection all increase HIV incidence, and condom use is protective and so adjust the models for these exposures [27].

\section{Methods}

Between 2002-2003 we enrolled youth aged 15-26 years into a cluster randomised controlled trial to evaluate the HIV prevention behavioural intervention Stepping Stones [26]. From the original 1415 enrolled women, we excluded those HIV infected at baseline $(n=159)$, those who were not sexually active before or during the period of observation $(\mathrm{n}=22)$, those lost to follow up at both 12 and 24 months $(\mathrm{n}=156)$, and two with missing data. We present here data from 1077 women ( $87.8 \%$ of sexually active HIV negative women in the cohort).

The trial had two arms. One received Stepping Stones, a 50 hour participatory intervention on sexual and reproductive health and HIV, delivered over 6-8 weeks. The control intervention was 3 hours on safer sex and HIV, delivered on one occasion. In all other respects the participants in the two arms were treated no differently. They were volunteers recruited from schools in 70 locations (clusters) in the Eastern Cape province of South Africa. The clusters were divided into seven geographically-defined strata and equal numbers of clusters in each strata were randomised between the two study arms. In each cluster, 15-25 youth of each sex were enrolled. Baseline, 12 and 24 month assessments included a face-to-face questionnaire and HIV and HSV2 blood tests. The cohort was maintained using details collected at enrolment, with follow-up conducted nationwide as necessary to trace youth who had moved. Further information on all assessments, study recruitment, access and ethical issues, including support for participants testing HIV positive, is presented elsewhere $[26,28]$. Ethical approval for the study was given by the University of Pretoria. All participants signed informed consent. All were offered their HIV test results and offered psychological support from a study nurse.

\section{Measures}

\section{Biological}

HIV serostatus at baseline was assessed with two rapid tests [29]. The Determine (Abbott Diagnostics, Johannesburg) test was used for screening and specimens testing positive were retested with UnigoldTM (Trinity Biotech, Dublin, Ireland). Indeterminate results were clarified using an HIV-1 screen ELISA (Genscreen) followed by two confirmatory ELISAs (Vironostika and Murex 1.2.0 if HIV positive). Towards the end of the second round of interviews collection of blood as dried spots was introduced for some participants to ease logistics and improve acceptability. In the third round of interviews most blood was thus collected. The specimens were tested with a screen and confirmatory ELISA (as above). In this analysis 746 (67.8\%) of the final HIV outcomes were from dried blood spots, equally distributed among participants remaining HIV negative and sero-converting $(67.8 \% \mathrm{v}$. $68.5 \%$ respectively).

A Glycoprotein G-based herpes simplex virus type 2 ELISA was used to test for herpes infection, Kalon (Kalon Biological Ltd., Aldershot, United Kingdom). A CAPTIA Herpes Simplex Virus (HSV) IgG Type Specific ELISA was used to resolve discrepant results.

\section{Measuring transactional sex}

Transactional sex was defined as occurring where a woman said that she had a sexual relationship (or act) motivated by his providing her (or her expectation that he would provide her) with food, cosmetics, clothes, transportation, items for children or family, school fees, somewhere to sleep, alcohol or a "fun night out", or cash [2]. A woman was said to have ever had transactional sex if she had ever had sex motivated by expectations of receiving one of the listed items, whether or not it was received (following Dunkle et al, 2004 [3]). The questions were asked separately for transactional sex with a main partner, a khwapheni and a once off sexual partner. We present measures of each in this paper, 
as well as one of transactional sex with a casual partner, where that is defined as either a khwapheni or once off.

\section{Other variables}

We measured age and completed years of schooling. Socioeconomic status was assessed using a scale derived for the study encompassing household goods ownership, food scarcity and perceived difficulty accessing money for a medical emergency (R100, about \$12). Each time they were interviewed we asked if they had a boyfriend, sex or been pregnant and measured duration of sexual activity from time since first sex. We asked about condom use during the last sexual encounter and whether problems had occurred (slipping off, put on later, breakage).

To measure partner numbers and types we asked separately about the number of main partners, of khwapheni and once-off partners. Khwapheni is a term in local idiom describing partners that are definitionally concurrent (and usually secret) for one or both of the partners involved. Number of partners was inquired for each category in the last year and lifetime. It was not possible to derive a continuous variable for partner numbers during follow up as we could not know whether those reported at 12 and 24 months were the same people. Thus the measure was dichotomised at 0 or 1 versus 2 or more sexual partners after examining the distribution and its relationship with HIV new infections. The age of the main partner was asked, and age difference calculated. A variable measuring whether the main partner at the 12 or 24 month interview was five or more years older during follow up was derived.

A sexual relationship power scale (10-items, Cronbach's alpha=0.73), previously shown to be associated with incident HIV among in South African women, was used to measure gender power equity $[27,30]$. Each item was assessed on a 4 point Likert scale and the measure was scored and categorised into tertiles of the measure. For the analysis the tertile with lowest equity was compared to the middle and higher ones.

The WHO violence against women instrument was used to measure physical partner violence (5-items) and sexual partner violence (4 items) over the past year or ever [31]. We coded physical or sexual violence into more than one episode versus none or only one, as this has been shown to be associated with incident HIV [27].

We derived variables for possible time-varying covariates during follow up. In each case we considered behaviour reported at either the 12 months interview (i.e. between baseline and 12 months) or at the 24 month interview (if she did not sero-convert at 12 months).

We hypothesised that transactional sex might be often with relatively older partners and also that women having transactional sex may have more partners. The former has been taken into account in the data analysis, but in order to take the latter into account we derived a three level variable to combine exposure to transactional sex with a casual partner (one off or on-going) and having two or more partners (c.f. Dunkle et al 2004 [32]). The reference category had less than two partners during follow up (or before HIV positivity). The first category had two or more partners but reported no transactional sex, and the second category had two or more partners and transactional sex with a casual partner.

\section{Data analysis}

Analyses were carried out using Stata 12.0 and draws on 1077 women who were HIV negative at baseline, had HSV2 results at baseline and were sexually active at baseline or became sexually active during the two years of follow up. All procedures took into account the study design, viewing the dataset as a cohort with a stratified, two stage structures with participants clustered within villages. There were 127 HIV seroconversions in 2036 person years of follow up, with an HIV incidence of 6.2 per 100 person years. For each participant we calculated the person years of exposure as the time from baseline to the last negative result if the person remained negative, or as the total time between any negative tests as well as half the time between the last negative and first positive test.

The social, demographic and relationship characteristics, HSV 2 prevalence and violence exposures were summarised as percentages (or means) with 95\% confidence limits, using standard methods for estimating confidence intervals from complex multistage sample surveys (Taylor linearization). Pearson's chi was used to test associations between categorical variables.

To account for clustering of women within villages, random effects (multilevel) models were fitted. Random effects Poisson models were built to test the hypothesis that measures of transactional sex predicted HIV incident infections. Each model included variables for established HIV risk factors i.e. age, the study treatment arm, stratum, baseline HSV2 status, relationship power and exposure to more than one episode of physical or sexual partner violence, correct condom use at last sex before the final HIV test or diagnosis and person years of exposure. We present incident rate ratios from Poisson models that included the different transactional sex and sexual behaviour variables. We also tested the models for the possibility of confounding or effect modification by education, SES, pregnancy, and duration of sexual activity, but found no substantial confounding or effect modification. We tested for interactions between all variables in the model and found none. We tested whether findings were depended on the partner number cut point, and whether they were different if number of partners at 12 months was used as a continuous variable and found they did not differ. We tested goodness of fit using the Poisson goodness of fit test. We confirmed the findings of associations for models with each sexual behaviour variable, by modelling survival time under observation using a Weibull model, with the same set of adjustment variables (findings not shown).

In order to test the second hypothesis we repeated the above procedure with a model with the three level variable transactional sex and partner number variable. We also built a model, again following the same procedure, with transactional sex with a casual partner as an additional adjustment variable and examined having a main partner 5 or more years older as the main explanatory variable of interest.

\section{Results}

Of the original set of HIV negative women, $12.6 \%$ were lost to follow up. These women were significantly older, more likely to have had a boyfriend and sex at baseline than those followed up (Table 1). They did not differ significantly from those followed up on measures of transactional sex with a casual partner or partner numbers. The mean age of the women retained was 18.4 years (range 15-24) at baseline. At baseline 30 (3.7\%) had never had a boyfriend, but 119 (10.8\%) had not yet had sex. The proportion interviewed at 12 months who had not had sex was $4.2 \%$, and $1.9 \%$ at 24 months. The latter group were then excluded from the analysis.

The women were mostly still in school (98.1\%), unmarried and their homes were poor (Table 2). Those who acquired HIV did not differ in age, education, or socio-economic status from those who did not, but there were more likely to have been pregnant (Table 2). 
Citation: Jewkes R, Dunkle K, Nduna M, Shai NJ (2012) Transactional Sex and HIV Incidence in a Cohort of Young Women in the Stepping Stones Trial. J AIDS Clinic Res 3:158. doi:10.4172/2155-6113.1000158

Page 4 of 8

\begin{tabular}{|c|c|c|c|}
\hline & Followed up & Lost to follow up & $p$ value \\
\hline & 1099 & 156 & \\
\hline & $\%(n)$ & $\%(n)$ & \\
\hline Age (years) & $18.40(18.24,18.56)$ & $18.78(18.50,19.06)$ & 0.013 \\
\hline Education: to grade 10 & $87.0(956)$ & $85.3(133)$ & 0.594 \\
\hline Socio-economic status (Mean, $95 \% \mathrm{Cl}$ ) & $0.0055(-0.12,0.13)$ & $-0.014(-0.221,0.194)$ & 0.853 \\
\hline Ever had a boyfriend & $96.4(1059)$ & $99.4(155)$ & 0.053 \\
\hline Ever had sex & $89.2(980)$ & $94.9(148)$ & 0.037 \\
\hline Duration of sexual activity (yrs) & $2.92(2.76,3.07)$ & $2.93(2.57,3.28)$ & 0.965 \\
\hline$>1$ episode of physical or sexual IPV & $23.0(253)$ & $25.0(39)$ & 0.565 \\
\hline $3+$ past year partners at baseline & $7.7(85)$ & $8.3(13)$ & 0.794 \\
\hline Ever transactional sex with a casual partner & $8.7(85)$ & $5.4(8)$ & 0.179 \\
\hline HSV2 at baseline* & $22.3(245)$ & $25.7(39)$ & 0.374 \\
\hline Intervention : Stepping Stones & $51.1(562)$ & $53.2(83)$ & 0.661 \\
\hline
\end{tabular}

* $\mathrm{N}=152$ lost to follow up

Table 1: Comparison of characteristics of the sample enrolled at baseline by whether they were followed up.

\begin{tabular}{|c|c|c|c|c|c|c|c|c|c|c|c|}
\hline & \multicolumn{5}{|c|}{ Incident HIV } & \multicolumn{5}{|c|}{ No incident HIV } & \multirow[b]{3}{*}{ p value } \\
\hline & $n=127$ & & & & & $n=950$ & & & & & \\
\hline & $\%$ & $\mathbf{n}$ & $\mathbf{N}$ & $95 \% \mathrm{Cl}$ & & $\%$ & n & $\mathbf{N}$ & $95 \% \mathrm{Cl}$ & & \\
\hline Age (Mean) & 18.5 & & & 18.3 & 18.8 & 18.4 & & & 18.2 & 18.5 & 0.323 \\
\hline Education: to grade 10 & 85.0 & 108 & 127 & 77.2 & 92.8 & 87.2 & 828 & 950 & 82.5 & 91.9 & 0.524 \\
\hline Socio-economic status (Mean) & -0.017 & & & -0.272 & 0.238 & -0.003 & & & -0.136 & 0.129 & 0.922 \\
\hline Had a pregnancy & 24.4 & 31 & 127 & 17.0 & 31.9 & 17.5 & 166 & 948 & 14.6 & 20.4 & 0.035 \\
\hline Relationship power: low equity & 40.7 & 50 & 123 & 31.0 & 50.3 & 30.2 & 271 & 897 & 26.4 & 34.0 & 0.023 \\
\hline$>1$ episode of physical or sexual IPV & 35.4 & 45 & 127 & 26.5 & 44.4 & 21.8 & 207 & 950 & 19.0 & 24.6 & 0.001 \\
\hline HSV2 at baseline & 40.9 & 52 & 127 & 31.5 & 50.4 & 20.3 & 193 & 950 & 17.5 & 23.1 & $<0.0001$ \\
\hline Intervention : Stepping Stones & 46.5 & 59 & 127 & 31.6 & 61.3 & 51.7 & 491 & 950 & 38.8 & 64.5 & 0.276 \\
\hline $\begin{array}{l}\text { Correct condom use at last sex before } \\
\text { final HIV result }\end{array}$ & 40.9 & 83 & 126 & 30.9 & 51.0 & 55.8 & 530 & 944 & 52.1 & 59.5 & 0.006 \\
\hline \multicolumn{12}{|l|}{ Sexual practices during follow up } \\
\hline $\begin{array}{l}\text { Partner age difference of } 5+\text { years during } \\
\text { follow up }\end{array}$ & 57.5 & 73 & 127 & 49.1 & 65.9 & 52.8 & 647 & 950 & 64.9 & 71.3 & 0.014 \\
\hline $2+$ partners during follow up & 52.0 & 66 & 127 & 41.8 & 62.1 & 36.8 & 350 & 950 & 34.1 & 39.6 & 0.004 \\
\hline Transactional sex with a once off partner & 2.4 & 3 & 127 & 0.0 & 5.0 & 0.4 & 4 & 945 & 0.0 & 0.8 & 0.141 \\
\hline $\begin{array}{l}\text { Transactional relationship with a main } \\
\text { partner }\end{array}$ & 19.7 & 25 & 127 & 12.7 & 26.6 & 12.5 & 118 & 945 & 9.8 & 15.2 & 0.040 \\
\hline $\begin{array}{l}\text { Transactional relationship with an on- } \\
\text { going secret partner }\end{array}$ & 12.6 & 16 & 127 & 5.6 & 19.6 & 4.6 & 43 & 945 & 2.9 & 6.2 & 0.019 \\
\hline $\begin{array}{l}\text { Transactional sex and multiple } \\
\text { partners during follow up : neither }\end{array}$ & 48.0 & 61 & 127 & & & 63.1 & 599 & 950 & & & 0.0003 \\
\hline $\begin{array}{l}2+\text { partners, no transactional sex with a } \\
\text { casual partner }\end{array}$ & 38.6 & 49 & 127 & & & 32.1 & 305 & 950 & & & \\
\hline $\begin{array}{l}\text { Transactional sex with a casual partner } \\
\text { and } 2+\text { partners }\end{array}$ & 13.4 & 17 & 127 & & & 4.8 & 46 & 950 & & & \\
\hline
\end{tabular}

Table 2: Socio-demographic and behavioural characteristics of women who did and did not acquire HIV over 2 years*.

They had experienced more partner violence, had more inequitable relationships and were more likely to have HSV2 at baseline. Those who sero-converted were less likely to have used a condom correctly at last sexual intercourse before their final HIV test during follow up.

The most common form of transactional sex was having a transactional relationship with a main partner. The second most common was a transactional relationship with an on-going, secret partner (a khwapheni). The number of women who had had transactional sex with a man as a once off event during follow up was very small $(n=7)$. The women who acquired HIV were more likely to have had a transactional relationship with a main partner, and a transactional relationship with a khwapheni. They were also were more likely to have two or more partners during follow up and a greater proportion had a main partner 5 or more years older.

The incidence of HIV and incidence rate ratio derived from the adjusted multivariable Poisson models are shown in Table 3. Women who had transactional sex with a once off partner and a khwapheni had a higher HIV incidence than those who did not. There was no difference in HIV incidence between those having a transactional relationship with a main partner and those who did not. 


\begin{tabular}{|c|c|c|c|c|c|c|c|}
\hline & $\begin{array}{c}\text { Person } \\
\text { years }\end{array}$ & $\begin{array}{c}\text { no. of } \\
\text { seroconverters }\end{array}$ & $\begin{array}{l}\text { Incidence per } \\
\text { person year, \% }\end{array}$ & Adjusted IRR* & $95 \% \mathrm{Cl}$ & & $p$ value \\
\hline \multicolumn{8}{|l|}{ Transactional sex with main partner during follow up } \\
\hline none & 1750 & 102 & 5.8 & 1.00 & & & \\
\hline any & 269 & 25 & 9.3 & 1.44 & 0.92 & 2.24 & 0.111 \\
\hline \multicolumn{8}{|l|}{$\begin{array}{l}\text { Transactional sex with a once off partner during follow } \\
\text { up }\end{array}$} \\
\hline none & 2016 & 124 & 6.1 & 1.00 & & & \\
\hline any & 13 & 3 & 23.7 & 3.29 & 1.02 & 10.55 & 0.046 \\
\hline \multicolumn{8}{|l|}{$\begin{array}{l}\text { Transactional sex with an on-going or casual partner } \\
\text { during follow up }\end{array}$} \\
\hline none & 1919 & 110 & 5.7 & 1.00 & & & \\
\hline any & 117 & 17 & 14.5 & 2.06 & 1.22 & 3.48 & 0.007 \\
\hline \multicolumn{8}{|l|}{$2+$ partners during follow up } \\
\hline none & 1243.0 & 61 & 4.9 & 1.00 & & & \\
\hline any & 793.0 & 66 & 8.3 & 1.37 & 0.96 & 1.98 & 0.086 \\
\hline \multicolumn{8}{|l|}{ Partner $5+$ years older during follow up** } \\
\hline none & 660.0 & 54 & 8.2 & 1.00 & & & \\
\hline any & 1376.0 & 73 & 5.3 & 0.73 & 0.50 & 1.05 & 0.085 \\
\hline $\begin{array}{l}\text { Transactional sex and multiple partners during follow } \\
\text { up : neither }\end{array}$ & 1241.0 & 61 & 4.9 & 1.00 & & & \\
\hline $2+$ partners, no transactional sex with a casual partner & 678.0 & 49 & 7.2 & 1.20 & 0.81 & 1.77 & 0.368 \\
\hline Transactional sex with a casual partner and $2+$ partners & 117.0 & 17 & 14.5 & 2.23 & 1.28 & 3.88 & 0.005 \\
\hline
\end{tabular}

** additionally adjusted for having transactional sex with a casual partner

* Poisson models adjusted for age, HSV2, relationship power, condom use, IPV exposure, treatment, stratum and person years of exposure

Table 3: Incidence and relative incidence of HIV infection in a cohort of women exposed to transactional sex and other risky practices.

Having a main partner five or more years older during follow up was not associated with a higher HIV incidence; neither was having two or more partners during follow up. The relationship between partner numbers and transactional sex with a casual partner is shown in the analysis with the three level variables. This showed that it was only those who had had transactional sex with a casual partner had a significantly higher HIV incidence.

\section{Discussion}

We have found that after adjusting for other HIV risk factors, young South African women who had transactional sex with a once off partner and those having a transactional relationship with a khwapheni had a greater HIV incidence. After adjustment for number of partners, those women who had transactional sex with a casual partner were still more likely to acquire HIV. Having an older main partner and having more partners alone did not elevate HIV incidence after adjustment for other variables. The overall incidence in our cohort $(6.2 \%)$ is very similar to that estimated nationally among women aged 15-24 years (6.5\%) [33].

Our findings about the importance of transactional sex support those of cross-sectional research from diverse populations including pregnant women in Soweto, South Africa and agricultural workers in Kenya $[8,30,32]$. They provide further evidence on temporal sequence, and evidence that the impact of transactional sex on HIV acquisition cannot just be explained through its impact on partner numbers, exposure to intimate partner violence nor on the age-differential. Our findings point to a causal relationship that needs to be explicitly addressed in HIV prevention programming.

Transactional sex may be motivated by basic survival and subsistence needs $[10,13,34,35]$ but this is not always the case and young women may also use it to bolster their self-esteem in the context of youth cultures which prioritise conspicuous consumption [10,34,3639]. Women in prostitution often claim to have more independence and power, including to insist on condom use, than women in transactional relationships [16], and in so doing they point to a particular type of vulnerability that financial or material need introduces into sexual relations. Where there is an absence of explicit negotiation and a bolstered sense of male entitlement, men perceive that gifts of cash result in a woman accepting sex on his terms, which are often without condoms and without space to assert preferences for monogamy and so forth [34,40-42].

There is a growing interest in international programming on structural interventions to prevention HIV acquisition by young women, in particular recently in conditional cash transfers (CCT). The Zomba district cash transfer intervention in Malawi had early findings of a reduction in pregnancy and early marriage and is believed to have reduced transactional sex [43] and the conditional cash transfer in Ifakara, Tanzania showed some impact on treatable STI infections [44]. So far the impact on HIV incidence is lacking, furthermore the findings suggest impact is at least dependant on the amount offered [44]. A further difficulty is that South Africa is the only country in Sub-Saharan Africa that has an advanced social security system that could even potentially implement conditional payments, and here the evidence suggests that doing so would be difficult as social grant fraud is a problem and so maintaining a 'conditional' aspect to payments would be hard. Thus the evidence of utility in real world contexts of these types of models in reducing HIV incidence has not yet been shown. The likely success of payment for health outcomes is predicated on a highly individualistic and rational model of drivers of sexual risk. Much research on sexuality in Africa suggests that this may have limitations as it ignores the role of social norms in sexual practice and messages of acceptability conveyed by members of a social network $[13,34,45]$ 
One indication of social norms related to transactional relationships is seen in family practices around the provision of basic necessities (or pocket money) to young women. Women often receive less than their brothers, if provided for at all, and there is an assumption that they will make up the deficit themselves $[14,18]$. Whilst it is valuable to further research CCT interventions, it may be mistaken to assume that they will provide all the answers to the problem of young women's engagement in transactional sex.

Successful interventions are likely to be complex and include addressing the gendered social norms related to transactional sex i.e. assumptions about men and the provider role $[12,16]$. The Stepping Stones participatory intervention did address transactional sex and there was evidence of reduced transactional sex among men (as givers of resources) one year after the intervention [26]. This suggests that some of the demand side of transactional sex may be amenable to intervention. More research is needed. The intervention did not effectively impact on the supply side, indeed women in the Stepping Stones arm reported more 12 months after the intervention than other women, which underscores the complexity of factors impacting on the supply side.

Supply side interventions need to address social norms on the acceptability of transaction, as well as meeting the material needs that are currently filled by sexual partners $[13,14]$. At a certain level supply side transactional sex is driven by economic scarcity [3], and so long term solutions will require strengthening education systems, keeping young women in school longer and better equipping them for work and income generation. However the women in the Stepping Stones study who engaged in transactional sex and had an elevated HIV risk were in school and most women in the study were very poor. This suggests there is scope for other forms of intervention as not all engaged in transactional sex. It is likely that there needs to be a range of interventions directed at young women, and their families, to change social norms, and promote women's independent access to resources to meet daily needs. This includes engagement with families around the risks of transactional sex and the potential for them to ameliorate these through changes in norms on resource distribution (pocket money). Further work developing and testing interventions to change social norms and remove the economic drivers of transactional sex is urgently needed.

There is a recognised problem of eliminating confounding in observational epidemiology, without over-adjusting the models [46], particularly given the limited number of new infections. Having tested the models extensively for confounding, interactions and effect modification, we are confident that we have presented models that have been appropriately constructed and fit the data well. This study has strengths and limitations. The cohort was comprised of volunteers and although retention was high, there was some loss to follow up. Those lost were older, but it is impossible to know whether this would have influenced the findings. The data were self-reported and may have been vulnerable to reporting bias, but this is unlikely to have been differential between HIV acquisition groups. We acknowledge that the measure of partner numbers should ideally have been continuous but it was not possible to derive this from the available data, further the measure of partner age did not take into account the age of casual partners. It is likely that the number of sexual encounters with a main partner would be greater than those of casual and so these partners are likely to be more important in HIV exposure. The cut point of two or more partners versus fewer did reflect the data in that both transactional sex and HIV new infections were significantly lower below two partners than above, and at 12 months only $7.4 \%$ of women reported having more than two partners in the past year so the cell size also warranted collapsing of categories.

The follow up data was interval censored and the model included the standard method of dealing with uncertainty about the time of HIV sero-conversion in such data. It is impossible to know when seroconversion did occur and so impossible to accurately estimate the errors in such an assumption, although we can suggest no reason to suppose these to be biased by exposure to transactional sex. This is a recognised and unavoidable problem [47], but we tried to ensure it did not result in spurious findings by confirming the results through two quite different approaches to model building. HIV new infections may have been slightly under-ascertained due to the window period and some women only being available at 12 and not 24 months for follow up. It is possible that using the Stepping Stones trial cohort may have introduced biases in this analysis, but we adjusted for study treatment arm and checked for interactions. There was no effect of treatment on HIV incidence in women [26].

\section{Conclusion}

We have shown that HIV incidence was higher among young rural South African women who had engaged in transactional sex with a casual partner, after adjusting for partner numbers. The finding also suggests that having casual sex with a once off partner was a risk factor for HIV, although in this study it was an infrequently reported practice. These findings compliment the findings of rural research from Kenya on HIV incidence and a broader body of cross-sectional evidence on the importance of transactional sex. Our findings do not support assertions that partner age difference and number of partners themselves were of equivalent importance among women in the study. HIV prevention interventions with young women are of considerable importance. Young women are very vulnerable and much less able to influence their own sexual risk than men of the same age [48]. These findings provide support for those who are investigating interventions to enable young women to avoid transactional sex, whether through change in social norms or economic empowerment. Donors and researchers must invest resources and energies in developing and testing new interventions to reduce transactional sex as a high priority in global HIV prevention.

\section{Acknowledgements}

We thank all the members of the Stepping Stones study team and the National Institute for Communicable Diseases for quality control, testing, and storage of specimens; the staff who worked on the project, members of the community advisory board and DSMB. Carl Lombard advised on the data analysis.

\section{Funding}

National Institute of Mental Health grant Nos [MH 64882-01, MH 6488204S1A1, 1R03MH085599] and the South African Medical Research Council.

\section{Author Contributions}

Rachel Jewkes: designed the Stepping Stones study and was the principal investigator, she analysed the data and wrote the paper; Kristin Dunkle contributed to the design of the study, assisted with the data management and assisted in the interpretation of the data and drafting of the paper; Mzikazi Nduna contributed to the design of the study and project management and approved the paper before submission; Nwabisa Jama contributed to the design of the study and implementation and approved the paper before submission.

\section{References}

1. Church S, Henderson M, Barnard M, Hart G (2001) Violence by Clients towards Female Prostitutes in Different Work Settings: Questionnaire Survey. BMJ 322: 524-525.

2. Dunkle KL, Jewkes R, Nduna M, Jama N, Levin J, et al. (2007) Transactiona sex with casual and main partners among young South African men in the rural 
Citation: Jewkes R, Dunkle K, Nduna M, Shai NJ (2012) Transactional Sex and HIV Incidence in a Cohort of Young Women in the Stepping Stones Trial. J AIDS Clinic Res 3:158. doi:10.4172/2155-6113.1000158

Eastern Cape: prevalence, predictors, and associations with gender-based violence.. Soc Sci Med 65: 1235-1248.

3. Dunkle KL, Jewkes RK, Brown HC, Gray GE, McIntyre JA, et al. (2004) Transactional sex among women in Soweto, South Africa: prevalence, risk factors and association with HIV infection. Soc Sci Med 59: 1581-1592.

4. Farley M, Barkan H (1998) Prostitution, Violence Against Women, and Posttraumatic Stress Disorder. Women \& Health 27: 37-49.

5. Beattie TS, Bhattacharjee P, Ramesh BM, Gurnani V, Anthony J, et al. (2010) Violence against female sex workers in Karnataka State, South India: Impact on health, and reductions in violence following an intervention program. BMC Public Health 10: 476.

6. Decker MR, McCauley HL, Phuengsamran D, Janyam S, Seage GR 3rd, et al. (2010) Violence victimisation, sexual risk and sexually transmitted infection symptoms among female sex workers in Thailand. Sexually Transmitted Infections 86: 236-240.

7. Romero-Daza N, Weeks M, Singer M (2003) 'Nobody Gives a Damn if I Live or Die': Violence, Drugs, and Street-Level Prostitution in Inner-City Hartford, Connecticut. Med Anthropol 22: 233-259.

8. Shaffer DN, Ngetich IK, Bautista CT, Sawe FK, Renzullo PO, et al. (2010) HIV-1 incidence rates and risk factors in agricultural workers and dependents in rural Kenya: 36-month follow-up of the Kericho HIV cohort study. J Acquir Immune Defic Syndr 53: 514-521.

9. Pettifor AE, Kleinschimdt I, Levin J, Rees HV, MacPhail C, et al. (2005) A community-based study to examine the effect of a youth HIV prevention intervention on young people aged 15-24 in South Africa: results of the baseline survey. Trop Med Int Health 10: 971-980.

10. Luke N (2003) Age and economic asymmetries in the sexual relationships of adolescent girls in sub-Saharan Africa. Stud Fam Plann 34: 67-86.

11. Luke N (2005) Investigating exchange in sexual relationships in sub-Saharan Africa using survey data. In: Jejeebhoy SJ, Shah I, Thapa S, editors. Sex Without Consent: Young People in Developing Countries. London: Zed Books.

12. Jewkes R, Morrell R, Sikweyiya Y, Dunkle K, Penn-Kekana L (2012) Transactional relationships and sex with a woman in prostitution: prevalence and patterns in a representative sample of South African men. BMC Public Health 12: 325

13. Leclerc-Madlala S (2003) Transactional sex and the pursuit of modernity. Social Dynamics: A journal of African Studies 29: 213-233.

14. Wamoyi J, Wight D, Plummer M, Mshana G, Ross D (2010) Transactional sex among young people in in rural northern Tanzania: an ethnography of Young women's motivations and negotiation. Reprod Health 7: 2

15. MacPhail A (2011) Trading Sugar: teenage girls, older men, sexual choice and gender inequality in the slums of Kibera, Kenya [Unpublished MA thesis]: University of Cape Town

16. Hunter M (2010) Love in the Time of AIDS. Inequality, gender and Right in South Africa Pietermaritzburg: University of KwaZulu-Natal Press.

17. Caldwell J, Caldwell P, Quiggin P (1989) The social context of AIDS in Subsaharan Africa. Population and Development Review 15: 185-234

18. Jewkes R, Morrell R (2012) Sexuality and the limits of agency among South African teenage women: theorising femininities and their connections to HIV risk practices. Soc Sci Med 74: 1729-1737.

19. Jewkes R, Dunkle K, Nduna M, Levin J, Jama N, et al. (2006) Factors associated with HIV sero-status in young rural South African women: connections between intimate partner violence and HIV. Int J Epidemiol 35: 1461-1468.

20. MacPhail C, Williams BG, Campbell C (2002) Relative risk of HIV infection among young men and women in a South African township. Int J STD AIDS 13: $331-342$

21. Ott MQ, Barnighausen T, Tanser F, Lurie MN, Newell ML (2011) Age-gaps in sexual partnerships: seeing beyond 'sugar daddies'. AIDS 25: 861-863.

22. Norris AH, Kitabi AJ, Worby E (2009) Alcohol and transactional sex: how risky is the mix? Soc Sci Med 69: 1167-1776.

23. Jewkes R, Sikweyiya Y, Morrell R, Dunkle K, Penn-Kekana L (2012) Men, prostitution and the provider role: understanding the intersections of economic exchange, sex, crime and violence in South Africa. PLoS One.
24. Jewkes R, Morrell R (2010) Gender and sexuality: emerging perspectives from the heterosexual epidemic in South Africa and implications for HIV risk and prevention. J Int AIDS Soc 13: 6.

25. Jewkes R, Morrell R, Sikweyiya Y, Dunkle K, Penn-Kekana L (in press) Men, sex and the provider role: Crime, violence, correlated psychological attributes associated with South African men's engagement in prostitution and transactional sex in South Africa. Plos One.

26. Jewkes R, Nduna M, Levin J, Jama N, Dunkle K, et al. (2008) Impact of stepping stones on incidence of HIV and HSV-2 and sexual behaviour in rura South Africa: cluster randomised controlled trial. BMJ 337: a506.

27. Jewkes R, Dunkle K, Nduna M, Shai N (2010) Intimate partner violence relationship gender power inequity, and incidence of HIV infection in young women in South Africa: a cohort study. Lancet 367: 41-48.

28. Jewkes R, Nduna M, Levin J, Jama N, Dunkle K, et al. (2006) A cluste randomised controlled trial to determine the effectiveness of Stepping Stones in preventing HIV infections and promoting safer sexual behaviour amongst youth in the rural Eastern Cape, South Africa: trial design, methods and baseline findings. Trop Med Int Health 11: 3-16.

29. World Health Organisation (2004) Rapid HIV tests: guidelines for use in HIV testing and counselling services in resource-constrained settings. Geneva: World Health Organisation.

30. Pulerwitz J, Gortmaker S, DeJong W (2000) Measuring Sexual Relationship Power in HIVISTD Research. Sex Roles 42: 637-660.

31. Garcia-Moreno C, Hansen HA, Ellsberg M, Heise L, Watts C (2005) WHO Multicountry Study on Women's Health and Domestic Violence Against Women. Geneva: World Health Organisation.

32. Dunkle KL, Jewkes RK, Brown HC, Gray GE, Mclntryre JA, et al. (2004) Gender-based violence, relationship power, and risk of HIV infection in women attending antenatal clinics in South Africa. Lancet 363: 1415-1421.

33. Shisana O, Rehle T, Simbayi. LC, Parker W, Zuma K, et al. (2005) South African National HIV Prevalence, HIV Incidence, Behaviour and Communication Survey. Cape Town: HSRC Press.

34. Hunter M (2002) The materiality of everyday sex: thinking beyond 'prostitution'. African Studies 61: 99-120.

35. Wojcicki JM (2002) Commercial sex work or ukuphanda? Sex-for-money exchange in Soweto and Hammanskrall area, South Africa. Cult Med Psychiatry 26: $339-370$.

36. Silberschmidt M, Rasch V (2001) Adolescent Girls, Illegal Abortions and 'SugarDaddies' in Dar es Salaam : Vulnerable Victims and Active Social Agents. Soc Sci Med 52: 1815-1826.

37. Leclerc-Madlala S (2001) Chasing King Cash could prove to be our undoing Mail and Guardian: South Africa.

38. Nyanzi S, Pool R, Kinsman J (2001) The negotiation of sexual relationships among school pupils in south-western Uganda. AIDS Care 13: 83-98.

39. Kaufman CE, Stavrou SE (2004) "Bus fare please": the economics of sex and gifts among young people in Urban South Africa. Culture, Health \& Sexuality 6: 377-391.

40. Kenyon C, Heywood M, Conway S (2001) Mainstreaming HIVIAIDS: Progress and challenges. In: Ntuli A, Suleman F, Barron P, McCoy D, editors. South African Health Review 2001. Durban: Health Systems Trust.

41. Auvert B, Ballard R, Campbell C, Carael M, Carton M, et al. (2001) HIV infection among youth in a South African mining town is associated with herpes simplex virus-2 seropositivity and sexual behaviour. AIDS 15: 885-898.

42. Meekers D, Calves AE (1997) "Main" girlfriends, girlfriends, marriage and money: the social context of HIV risk behavior in sub-Saharan Africa. Health Transit Rev 7: 361-375.

43. Baird S, Chirwa E, Mclntosh C, Ozler B (2012) The short-term impacts of schooling conditional cash transfer program on the sexual behavior of young women. Health Econ 19: 55-68.

44. de Walque D, Dow WH, Nathan R, Abdul R, Abilahi F, et al. (2010) Incentivising safe sex: a randomised trial of conditional cash transfers for HIV and sexually transmitted infection prevention in rural Tanzania. BMJ Open 2: e000747.

45. Nkosana J, Rosenthal D (2007) The dynamics of intergenerational sexua 
Citation: Jewkes R, Dunkle K, Nduna M, Shai NJ (2012) Transactional Sex and HIV Incidence in a Cohort of Young Women in the Stepping Stones Trial. J AIDS Clinic Res 3:158. doi:10.4172/2155-6113.1000158

relationships: the experience of schoolgirls in Botswana. Sex Health 4: 181187.

46. Doll R (2002) Proof of causality. Deduction from epidemiological observation. Perspect Bio Med 45: 499-515.

47. Lindsey JC, Ryan LM (1998) Tutorial in biostatistics methods for intervalcensored data. Stat Med 17: 219-238.

48. Jewkes R, Wood K, Duvvury N (2010) "I woke up after I joined Stepping Stones": meanings of a HIV behavioural intervention in rural South African young people's lives. Health Edu Res 25: 1074-1084 